\title{
High mobility reduces beta-diversity among orthopteran communities - implications for conservation
}

\author{
LORENZO MARINI, ${ }^{1,2}$ ERIK ÖCKINGER, ${ }^{2}$ ANDREA BATTISTI ${ }^{1}$ and \\ RICCARDO BOMMARCO ${ }^{2}{ }^{1}$ Department of Environmental Agronomy and Crop Production, University \\ of Padova, Padova, Italy and ${ }^{2}$ Department of Ecology, Swedish University of Agricultural Sciences, Uppsala, Sweden
}

\begin{abstract}
The analysis of $\beta$-diversity, i.e. species turnover, across space is central to a wide array of ecological and evolutionary topics, also providing critical information to conservation planning. Although dispersal limitation has been demonstrated to play an important role in determining insect community structure, very little research has been done to test whether mobility might affect the diversity distribution of species across multiple spatial scales.

2. We considered orthopterans (Ensifera and Caelifera) inhabiting hay meadows to test whether species mobility modifies $\beta$-diversity patterns across three nested spatial scales $\left(1-\mathrm{m}^{2}\right.$ plots within meadow, 1000- $\mathrm{m}^{2}$ meadows within landscape, and 19.6$\mathrm{km}^{2}$ landscapes within a region) and along a gradient of management intensity.

3. Orthopteran community composition varied most significantly over broader spatial scales. Larger proportion of regional $\gamma$-diversity was mainly composed of $\beta$-diversity at the landscape scale, whereas this proportion was smaller at the plot and meadow scale.

4. Mobility, but not management, strongly modified $\beta$-diversity patterns. Sedentary species contributed to a greater proportion of $\beta$-diversity across all the investigated scales compared with mobile species.

5. Measures currently included in most agri-environment schemes have only focused on the extensive management at the field scale. Our results imply that orthopteran diversity would benefit from maintaining extensively managed meadows scattered throughout the whole region, as the loss of species-rich isolated grassland patches due to abandonment or eutrophication might cause severe reductions of the regional species pool. Increasing connectivity might be also considered as a complementary measure to increase species occupancy and population persistence, particularly for sedentary species.
\end{abstract}

Key words. Additive partitioning, agri-environment scheme, Alps, dispersal ability, grassland, habitat management, hay meadow, insect conservation, Orthoptera, species turnover.

\footnotetext{
Correspondence: Lorenzo Marini, University of Padova, Department of Environmental Agronomy and Crop Production, Viale dell'Università 16, 35020 Legnaro, Padova, Italy.

E-mail: lorenzo.marini@unipd.it
}

\section{Introduction}

Management intensification has been recognised amongst the main causes of the current decline of grassland insect diversity. However, intensification exerts its influence at multiple spatial scales (Marini et al., 2009a). The management of single fields 
might have an effect at small spatial scale by altering habitat quality, but also at larger spatial scale by modifying landscape composition and configuration (Tscharntke et al., 2005).

The partitioning of $\gamma$-diversity into $\alpha$-diversity and $\beta$-diversity components (Lande, 1996) provides an analytical framework to investigate how species diversity varies across multiple spatial scales (Gering et al., 2003) and environmental gradients (e.g. Gabriel et al., 2006; Klimek et al., 2008). In particular, $\beta$-diversity, which quantifies the change or turnover, in species across space is central to a wide array of ecological and evolutionary topics, also providing critical information to conservation planning (McKnight et al., 2007; Novotny, 2009). Although the number of species in a local community ( $\alpha$-diversity) often contributes to the relative conservation importance of single areas, it is the species turnover between sites that might indicate the optimal spatial arrangement of conservation areas (Summerville et al., 2003)

Insects are important components of grassland biodiversity, and interact with the landscape by dispersal. Mobility appears as a strong predictor of widespread success or decline of insect populations (Kotiaho et al., 2005). In general poor dispersers seem to be more prone to extinction and range contractions imposed by several human-induced processes such as fragmentation or eutrophication (Reinhardt et al., 2005; Öckinger et al., 2009, 2010; Bommarco et al., 2010; Ekroos et al., 2010; Marini et al., 2010). As mobility might be important in shaping species occupancy patterns (Kunin \& Gaston, 1993; Nieminen et al., 1999; Cowley et al., 2001; Gaston \& Blackburn, 2003), we expected that this trait should also modify species turnover across space. For instance, the proportion of species shared between two sites often decreases as the distance separating them increases, i.e. distance decay of similarity (Nekola \& White, 1999; Morlon et al., 2008). This pattern can be partly explained by increasing dissimilarity in environmental features with increasing distance (effects of niche-based processes) (Loreau, 2000) and partly by landscape configuration that dictates the dispersal rates of organisms between sites (effects of dispersal-based processes) (Nekola \& White, 1999). In the latter case, a prediction that arises from the metapopulation theory suggests that species with higher mobility should have high levels of occupancy for their abundance (Hanski, 1999; Gaston \& Blackburn, 2003). This should affect species spatial turnover by reducing $\beta$-diversity due to the larger exchange of individuals between populations. However, very little research has been done to test whether mobility might affect the diversity distribution of species across multiple spatial scales (but see Summerville et al., 2006; Ekroos et al., 2010).

In this study, orthopterans inhabiting hay meadows were chosen as a model system to test how mobility modifies $\beta$-diversity patterns across multiple spatial scales and along a gradient of management intensity. We considered three nested spatial scales $\left(1-\mathrm{m}^{2}\right.$ plots within meadow, $1000-\mathrm{m}^{2}$ meadows within landscape, and $19.6-\mathrm{km}^{2}$ landscapes within a region), corresponding to three different scales at which local stakeholders might apply conservation measures in managed grasslands, i.e. management guidelines at the field scale or managing the whole landscape at the regional scale. We tested the hypothesis that high mobility reduces $\beta$-diversity due to a homogenising effect of dispersal. As the different spatial scales have also been chosen to match the scales at which conservation measures are normally applied, our results will provide relevant information to manage grasslands for orthopteran conservation.

\section{Materials and methods}

\section{Study area}

The field survey was carried out in 2007 in the Province of Trento $\left(6200 \mathrm{~km}^{2}\right)$, in north-eastern Italy. In 2007, the area covered by hay meadows was c. 16000 ha. In this study, only montane meadows managed for hay production for at least 20 years (permanent meadows) were included. Meadows were fertilised with liquid or farmyard manure and only mown. The meadows are typically small (less than one ha), spatially scattered and interspersed with other management units belonging to different farms. The landscape was mainly composed of a grasslandforest mosaic.

\section{Sampling design}

To identify diversity pattern at different spatial scales, a nested sampling design was applied (Fig. 1). Based on official data of the Agriculture Department of the Province of Trento, we brought together information on meadow and topography in a GIS. Then, four classes of management intensity were defined. The four classes were defined on the basis of topographic slope, mowing frequency, soil fertility and sward height (proxy for productivity). The four classes varied from flat, high-productive intensively managed meadows to steep, lowproductive, extensively managed meadows (Table 1). Both management intensity and slope are known as important factors affecting $\alpha$-diversity of orthopterans in hay meadows (Marini et al., 2009a). For each management class, 11 nonoverlapping landscape sectors were selected (2.5-km radius) (Fig. 1a, macroscale). Then, within each landscape, three meadows belonging to the same management class were sampled (Fig. 1b, mesoscale). In total, 44 meadow triplets were sampled across the whole study region. We tried to keep the distance between the landscape sectors and the meadows within the sectors more or less equal. The landscapes were also selected to obtain an interspersed distribution of the different management classes. This would reduce potential biases due to different distances between sites belonging to different management classes. The elevation was similar between meadows at the mesoscale (i.e. the three meadows within each landscape had similar elevation), whereas it varied between landscapes from a minimum of 240 to a maximum of $1380 \mathrm{~m}$. However, there was no significant difference in mean elevation between the four management classes (Table 1). Overall, 132 meadow parcels were sampled across the whole study region. The meadow size ranged from 1.2 to 4.5 ha. A plot of $25 \times 40 \mathrm{~m}\left(1000 \mathrm{~m}^{2}\right)$ was placed in each meadow, where we carried out the surveys. Within each meadow, orthopteran diversity was sampled using $241-\mathrm{m}^{2}$ plots (Fig. 1c, microscale) (see below for more details). 
(a) Macroscale (landscape)

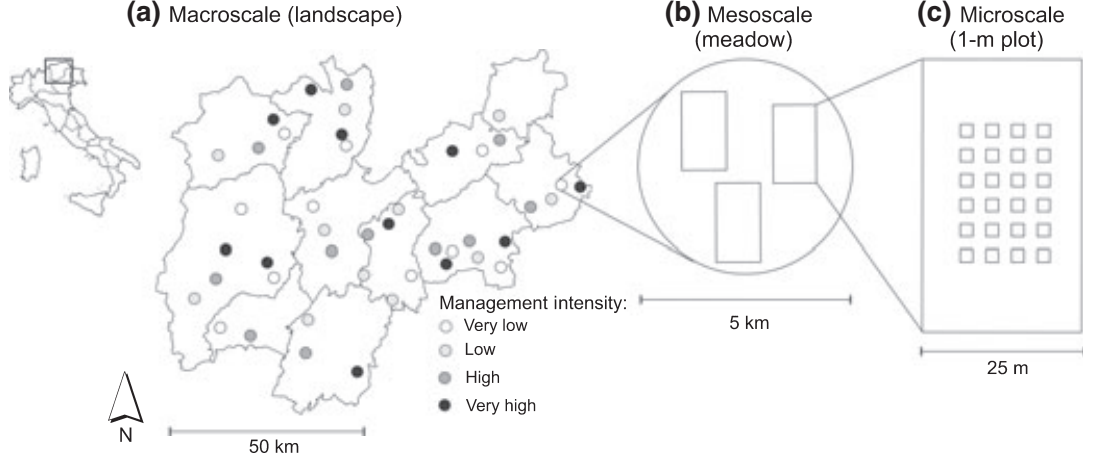

Fig. 1. Nested sampling design performed at three spatial scales: (a) macroscale (landscape), (b) mesoscale (meadow) and (c) microscale $\left(1-\mathrm{m}^{2}\right.$ plot). We sampled 11 landscapes for each management classes. The three meadows within each landscape belonged to the same management class.

Table 1. Comparison of mean values of our three indicators of management intensity and topographic slope between the four management intensity classes.

\begin{tabular}{|c|c|c|c|c|c|}
\hline \multirow[b]{2}{*}{ Sampled meadows $(n=132)$} & \multicolumn{4}{|l|}{ Management intensity } & \multirow[b]{2}{*}{$\mathrm{P}^{\star}$} \\
\hline & Very high $(n=33)$ & $\operatorname{High}(n=33)$ & Low $(n=33)$ & Very low $(n=33)$ & \\
\hline Number of cuts per year & 2.5 & 2.3 & 2.0 & 1.8 & $<0.01$ \\
\hline Soil Olsen $\mathrm{P}\left(\mathrm{mg} \mathrm{kg}^{-1}\right)^{*}$ & 68.5 & 67.0 & 51.1 & 41.2 & $<0.01$ \\
\hline Vegetation height $(\mathrm{cm})^{\dagger}$ & 33.0 & 33.3 & 25.9 & 22.7 & $<0.01$ \\
\hline Meadow slope $\left({ }^{\circ}\right)$ & 2.5 & 7.9 & 14.0 & 19.0 & $<0.01$ \\
\hline Elevation $(\mathrm{m})$ & 829 & 891 & 843 & 883 & n.s. \\
\hline
\end{tabular}

*Exchangeable Olsen $\mathrm{P}_{2} \mathrm{O}_{5}(\mathrm{P})$ (Olsen et al., 1954) measured on eight samples taken at a depth of 0-20 cm, after removing the organic layer, and bulked prior to analyses.

${ }^{\dagger}$ Vegetation height was measured using a drop-disc method (Stewart et al., 2001).

${ }^{\ddagger} P$-value from a one-way ANova.

\section{Orthopteran surveys}

We sampled Orthoptera (Ensifera and Caelifera) by visiting the 132 meadows during the periods of maximum activity and density of the species (between end of July and the end of August). Surveys took place between 10.00 and $17.00 \mathrm{~h}$ on warm sunny days that did not follow a day of high rainfall. In each meadow, orthopteran species richness and abundance was determined by using a 'box quadrate' with high sides (Gardiner et al., 2005). We used a white quadrate sampler that is a box with open top and bottom, with a side length of $1.0 \mathrm{~m}$, and a height of $0.75 \mathrm{~m}$. Within each meadow, 24 samplings were carried out by laying the box down rapidly in a vertical position, and therewith capturing all the individuals within the sampler. The nomenclature follows Fontana et al. (2005).

\section{Mobility}

As a measure of mobility of the orthopteran species, we used the index developed by Reinhardt et al. (2005) for Germany. This classification includes the following three classes: sedentary, intermediate disperses, and mobile species (Table 2). All apterous and brachypterous species were classified as sedentary, whereas spe- cies flying readily were assigned as mobile. For species showing wing dimorphism, we adopted the most common form. We acknowledge that mobility is not a fixed trait, and that it may differ between and within populations depending on habitat spatial configuration and population history (Poniatowski \& Fartmann, 2008). However, we used broad mobility classes, assuming that the degree of intra-specific variation was small compared with the variation between mobility classes (see also Öckinger et al., 2009; Marini et al., 2010). To further reduce potential bias, intermediate dispersers (whose classification typically was more problematic than the sedentary and mobile species) were excluded from the analyses. This allowed us to focus on the contrast between mobile and sedentary species. The species not reported by Reinhardt et al. (2005) were classified on the basis of information on taxonomic affinities, body size, and wing development (Fontana et al., 2002). Using these criteria, we located, for each of the twelve non-classified species, the most taxonomically similar one included in Reinhardt et al. (2005) for Germany, and then we assigned it the same value. We also classified species either as habitat specialists or generalists following Reinhardt et al. (2005), to test whether sedentary species were more likely to be habitat specialists than mobile species. Within our Orthoptera species pool, we found that habitat specialisation and mobility were independent life-history traits (Fisher's exact test, $P=0.448$ ). 
Table 2. Species list (from the most to the least frequent species), mobility, and habitat specialisation classification (according to Reinhardt et al., 2005), species occupancy (occ. \%) at the mesoscale (\% of the 132 meadows occupied), and total abundance in the four management intensity classes.

\begin{tabular}{|c|c|c|c|c|c|c|c|}
\hline \multirow[b]{2}{*}{ Species } & \multirow[b]{2}{*}{ Mobility } & \multirow[b]{2}{*}{ Specialisation } & \multirow[b]{2}{*}{ Occ. $(\%)$} & \multicolumn{4}{|c|}{ Management intensity } \\
\hline & & & & Very high & High & Low & Very low \\
\hline Chorthippus dorsatus & Mobile & Generalist & 87.9 & 249 & 583 & 44 & 498 \\
\hline Chorthippus parallelus & Mobile & Generalist & 86.4 & 446 & 539 & 352 & 61 \\
\hline Glyptobothrus biguttulus & Mobile & Generalist & 60.6 & 27 & 239 & 241 & 151 \\
\hline Stauroderus scalaris & Mobile & Generalist & 28.8 & 2 & 11 & 43 & 11 \\
\hline Euthystira brachyptera & Intermediate & Specialist & 27.3 & 18 & 8 & 94 & 73 \\
\hline Gryllus campestris & Sedentary & Specialist & 23.5 & 2 & 11 & 18 & 2 \\
\hline Decticus verrucivorus & Sedentary & Specialist & 20.5 & 1 & 5 & 23 & 22 \\
\hline Omocestus rufipes & Sedentary & Generalist & 18.2 & 2 & 1 & 81 & 172 \\
\hline Ruspolia nitidula* & Mobile & Generalist & 16.7 & 21 & 21 & 22 & 34 \\
\hline Stenobothrus lineatus & Intermediate & Specialist & 15.9 & 1 & 2 & 37 & 35 \\
\hline Pholidoptera griseoptera & Sedentary & Generalist & 15.2 & 2 & 7 & 17 & 2 \\
\hline Bicolorana bicolor & Mobile & Specialist & 11.4 & 4 & 7 & 1 & 2 \\
\hline Platycleis grisea & Intermediate & Specialist & 10.6 & 1 & & 15 & 6 \\
\hline Glyptobothrus brunneus & Mobile & Specialist & 9.8 & 12 & 21 & 12 & 3 \\
\hline Glyptobothrus mollis & Mobile & Specialist & 9.1 & 4 & 1 & 16 & 3 \\
\hline Tetrix tenuicornis & Sedentary & Specialist & 8.3 & 1 & 2 & 5 & 1 \\
\hline Dirshius haemorrhoidalis & Sedentary & Specialist & 7.6 & & 7 & 5 & 15 \\
\hline Tettigonia cantans & Intermediate & Generalist & 7.6 & 1 & 2 & 2 & 11 \\
\hline Eucorthippus declivus* & Mobile & Specialist & 6.8 & 21 & 1 & 36 & 1 \\
\hline Gomphocerus rufus & Intermediate & Generalist & 6.8 & 1 & 1 & 9 & 35 \\
\hline Phaneroptera falcata & Mobile & Specialist & 5.3 & & & 6 & 9 \\
\hline Oedipoda caerulea & Mobile & Specialist & 4.5 & & & 4 & 4 \\
\hline Omocestus viridulus & Intermediate & Generalist & 4.5 & 4 & 1 & & 1 \\
\hline Tetrix subulata & Mobile & Specialist & 4.5 & 2 & & 12 & 3 \\
\hline Parapleurus alliaceus* & Intermediate & Specialist & 3.8 & 6 & 3 & 1 & \\
\hline Tetrix bipuctata & Sedentary & Specialist & 3.8 & & & 3 & 3 \\
\hline Arcyptera fusca & Sedentary & Generalist & 3 & & & 8 & 9 \\
\hline Leptophyes boscii* & Intermediate & Specialist & 3 & & & 3 & 2 \\
\hline Pholidoptera falcata & Sedentary & Specialist & 2.3 & & 1 & & 3 \\
\hline Roeseliana roeseli & Sedentary & Specialist & 2.3 & 3 & 1 & & \\
\hline Tettigonia viridissima & Mobile & Generalist & 2.3 & & & 3 & \\
\hline Kisella irena* & Sedentary & Specialist & 1.5 & & & 1 & 1 \\
\hline Nemobius sylvestris & Sedentary & Specialist & 1.5 & & 2 & 1 & \\
\hline Pachytrachis striolatus* & Sedentary & Specialist & 1.5 & & & 5 & \\
\hline Pholidoptera aptera & Sedentary & Generalist & 1.5 & & & 1 & 1 \\
\hline Tetrix bolivari* & Sedentary & Specialist & 1.5 & & & & 2 \\
\hline Xiphidion discolor* & Intermediate & Specialist & 1.5 & & & 2 & \\
\hline Barbitistes serricauda* & Sedentary & Specialist & 0.8 & & & & 1 \\
\hline Calliptamus italicus & Intermediate & Specialist & 0.8 & & & & 12 \\
\hline Calliptamus siciliae* $^{*}$ & Intermediate & Specialist & 0.8 & & & 4 & \\
\hline Ephippiger vicheti* & Sedentary & Specialist & 0.8 & & & & 1 \\
\hline Glyptobothrus apricarius & Mobile & Specialist & 0.8 & & & & 5 \\
\hline Leptophyes albovittata & Mobile & Specialist & 0.8 & & & 1 & \\
\hline Psophus stridulus & Sedentary & Specialist & 0.8 & & & 1 & \\
\hline Tettigonia caudata* & Intermediate & Specialist & 0.8 & 1 & & & \\
\hline
\end{tabular}

*Species not included in Reinhardt et al. (2005) were classified according to Fontana et al. (2002).

Scales and additive partitioning of species diversity

We additively decomposed the total observed $\gamma$-diversity into diversity components within and among sampling units $(\alpha-$ and $\beta$-diversity, respectively) separately for each management classes at the micro-, meso- and macroscale (Fig. 1). Within the context of this study, orthopteran species richness was used as a measure of species diversity. At the microscale, $\alpha-\beta$ - and $\gamma$ components of diversity were calculated in $31681 \mathrm{~m}^{2}$ plots (792 for each management class, respectively); at the mesoscale in 132 meadow parcels (33 for each management classes), and at the macroscale in 44 landscape sector (11 for each 
management class). The $\alpha$-diversity (within-unit diversity) was the average number of species found in a sampling unit (plot, meadow, and landscape). The $\gamma$-diversity was the total number of species found in the pooled sampling units. For the three spatial scales, $\beta$-diversity (between-unit diversity) was calculated by subtracting $\alpha$ from $\gamma$ (Gering et al., 2003). As $\alpha$ - and $\beta$-diversity components were expressed in the same units of species richness, their contribution to total observed $\gamma$-diversity can be compared directly.

\section{Data analysis}

To test if the proportion of $\beta$-diversity ( $\%$ of $\gamma$-diversity within the same spatial scale) components differs between management classes and between mobile and sedentary species at micro-, meso- and macroscale, General Linear Mixed Models were used (SAS Proc Mixed, Littell et al., 1996) with mobility and management as fixed effects. The random structures were defined to account for sampling nestedness. At the microscale, meadow identity nested within landscape sectors was included as a random factor, and at the mesoscale, landscape sector was included as a random factor. The ratio $\beta / \gamma(\operatorname{arcsine}(\sqrt{ })$-transformed) within each spatial scale (i.e. $\beta$-micro $/ \gamma$-micro, $\beta$-meso $/ \gamma$-meso, and $\beta$-macro $/ \gamma$-macro) were used as response variables.

\section{Results}

Overall, 45 orthopteran species were found (27 Caelifera and 18 Ensifera) in the 132 meadows. Fifteen species were mobile, 19 sedentary, and 12 were intermediate dispersers. Chorthippus parallelus and $C$. dorsatus were the most abundant species, followed by Glyptobothrus biguttulus, Omocestus rufipes and Eutistyra brachyptera. The total number of species ( $\gamma$-macro) was higher within the low intensity management classes (Fig. 2). Eighty percent of the overall number of species found was observed in the very low intensity management class, whereas only $50 \%$ was found on very intensively managed meadows. The species found in the very high intensity class was almost completely nested in the species pool found in the very low intensity class, i.e. no species were strictly associated with the intensively managed meadows. Considering all the species together, the proportion of $\beta$-diversity of the regional $\gamma$-diversity varied between the three spatial scales. $\beta$-diversity decreased passing from the macro-, to the meso-, and microscale (the mean values are indicated in Fig. 2).

The patterns in species turnover within scale $(\%$ of $\beta$ - of $\gamma$-diversity within each scale) varied between sedentary and mobile species. At all three spatial scales, $\beta$-components $(\%$ of $\beta$ - of $\gamma$-diversity) were larger for sedentary than for mobile species (Table 3), i.e. there was higher species turnover between plots, meadows and landscapes. At micro- and macroscale, but not at the mesoscale, there were also non-significant tendencies to lower $\beta$-diversity with decreasing intensity of management. The interaction between mobility and management class was not significant at any of the investigated spatial scales.

\section{Discussion}

Our study indicates that the three investigated scales contributed differently to the partitioning of the regional $\gamma$-diversity along our management gradient and that orthopteran community composition varied most significantly over broader spatial scales. Mobility strongly modified $\beta$-diversity patterns of orthopterans, where sedentary species contributed to a greater proportion of $\beta$-diversity across different scales compared with mobile species. The orthopteran communities inhabiting intensively managed meadows were strongly nested and were a subset of those inhabiting extensively managed meadows.

\section{Scales and partitioning of the total $\gamma$-diversity}

Larger proportion of total $\gamma$-diversity (overall number of species in the study area) was composed of $\beta$-diversity at the macroscale (landscape), whereas this proportion was smaller at the microscale (plot) and mesoscale (meadow). The observed $\beta$-diversity patterns at each scale was probably the result of both environmental heterogeneity, species niche differentiation (Loreau, 2000) and dispersal limitation processes (Nekola \& White, 1999). Separating these factors for explaining species distribution across scale is difficult, although we did test for certain important environmental variables such as slope and management intensity. We surmise from our results that mobility and dispersal processes are important at all scales, but perhaps especially important determinants for beta-diversity at small and intermediate scales. The distance between sampling units was more or less constant within each scale of analysis, although it increased passing from a few metres between 1-m plots, to 0.5 $1.5 \mathrm{~km}$ between meadows and to several kilometres between landscape sectors. The large $\beta$-diversity at the macroscale compared with the meso- and microscale concurs with the distance decay of similarity hypothesis (Nekola \& White, 1999; Morlon et al., 2008). Longer distances between landscapes than between meadows might increase dispersal limitation and therefore lead to different species pool adapted to local conditions. These results generally confirm the observations of several previous studies that indicate that insect community composition varies most significantly over broader spatial scales, even when total species richness does not (e.g. Summerville et al., 2003, 2006).

At the microscale (1-m plot), we found low species turnover between plots within meadows. Although plots within meadow may vary in microclimate and vegetation architecture, orthopteran species usually exploit the whole meadows and do not respond to environmental heterogeneity at such fine spatial scale (Ingrisch \& Köhler, 1998). At the mesoscale (meadow), the relatively low level of $\beta$-diversity can be a consequence of our sampling design in which meadows with similar slope and management were selected within a landscape of $2.5 \mathrm{~km}$ radius. Keeping management constant, the relatively short distances between meadows $(0.5-1.5 \mathrm{~km})$ might have contributed to community homogenisation, as this distance range is comparable with orthopteran dispersal. The macroscale (landscape) contributed a large proportion of $\beta$-diversity with values up to $90 \%$ of 
Components of diversity

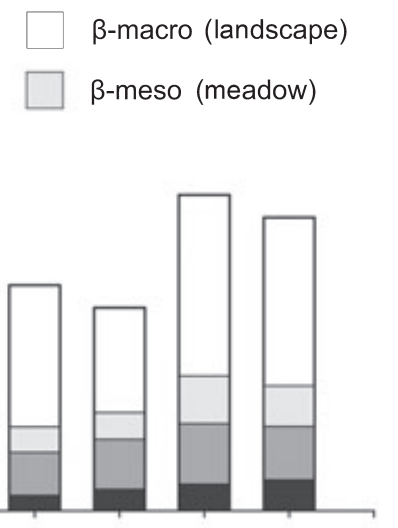
$\square$ ß-micro (plot)
a-micro
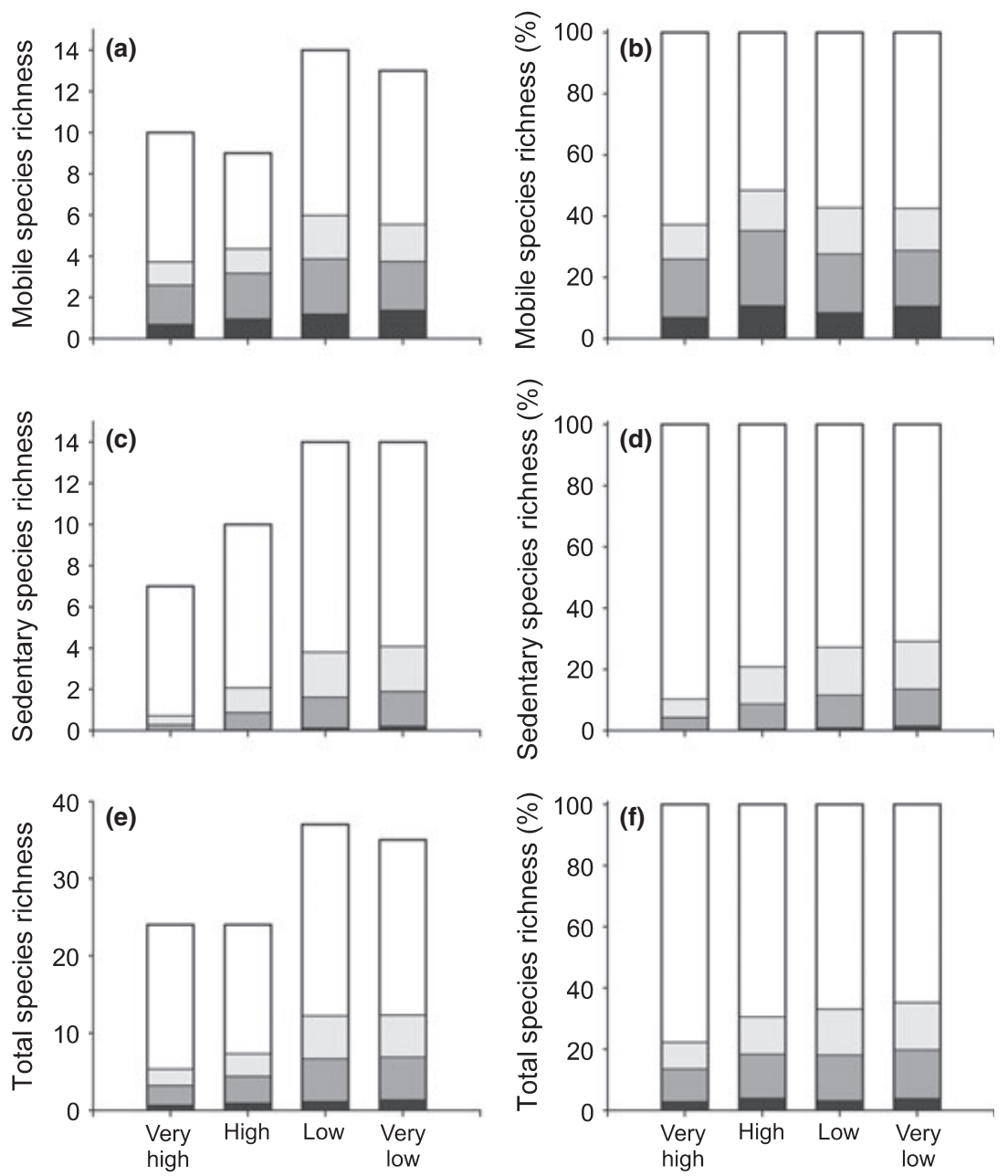

Management intensity
Fig. 2. Additive partitioning of orthopteran species richness at the three spatial scales (microscale: 1- $\mathrm{m}^{2}$ plot; mesoscale: meadow, macroscale: landscape) within the four management classes. Mean $\alpha$ - and $\beta$ components for (a) mobile, (c) sedentary and (e) total species richness. We show also the relative contributions (i.e. $\%$ of total $\gamma$ ) of the $\alpha$-component and $\beta$-component in panels (b), (d) and (f). the total $\gamma$-diversity. Landscape may vary a lot in several features such as topography, climate, habitat diversity, or history. All these factors are known to influence local assemblages and composition of orthopteran communities (Schouten et al., 2007;
Gardiner \& Hassall, 2009; Schirmel et al., 2010). In particular, it is well known that orthopteran communities shift strongly along mountain elevation gradients (Alexander \& Hilliard, 1969). As the landscape sectors were located along a relatively extended

Table 3. General linear mixed model results, testing the effects of management and mobility on $\beta$-diversity patterns. We tested $\beta$-micro $(\%$ on $\gamma$-micro) at the mesoscale (meadow) $(n=132)$, (b) $\beta$-meso $(\%$ on $\gamma$-meso) at the mesoscale (landscape) $(n=44)$, and $\beta$-macro ( $\%$ on $\gamma$-macro).

\begin{tabular}{|c|c|c|c|c|c|c|c|c|c|}
\hline & \multicolumn{2}{|c|}{ (a) Microscale } & \multirow[b]{2}{*}{$P$} & \multicolumn{2}{|c|}{ (b) Mesoscale } & \multirow[b]{2}{*}{$P$} & \multicolumn{2}{|c|}{ (c) Macroscale } & \multirow[b]{2}{*}{$P$} \\
\hline & d.f. & $F$ & & d.f. & $F$ & & d.f. & $F$ & \\
\hline Mobility & 1,73 & 87.1 & $<0.001$ & 1,31 & 68.6 & $<0.001$ & 1,3 & 40.2 & 0.008 \\
\hline Management & 3,73 & 2.17 & 0.099 & 3,31 & 0.47 & 0.71 & 3,3 & 8.50 & 0.056 \\
\hline Management $\times$ Mobility & 3,73 & 1.29 & 0.29 & 3,31 & 1.58 & 0.21 & - & - & - \\
\hline
\end{tabular}


elevation gradient (range: $240-1380 \mathrm{~m}$ ), the differences in temperature between low- and high-elevation areas might have played an important role in increasing species turnover at the broad spatial scale.

\section{Mobility effect on $\beta$-diversity patterns}

Mobility, but not management, strongly modified $\beta$-diversity patterns within each of the investigated scales, reducing species turnover between plot, meadows and landscapes, respectively. High dispersal probably worked as homogenising force at all spatial scales. The lack of management effects indicate that niche-based processes were probably less important than dispersal limitation in shaping $\beta$-diversity patterns. Dispersal limitation has been demonstrated to play an important role in determining insect community structure, especially in highly disturbed or fragmented systems (Thomas, 2000; Öckinger et al., 2009, 2010; Bommarco et al., 2010; Marini et al., 2010). Summerville et al. (2006), using body size as a proxy for mobility, found that species turnover did not vary between small and large species, although they also indicated that this trait might not be a good proxy for species dispersal and occupancy in moths. Our results generally concur with those of Ekroos et al. (2010), who found that agricultural intensification decreases $\beta$-diversity of butterflies as a result of an increasing proportion of habitat generalists and increasing average mobility in the butterfly communities. Highly mobile species are expected to be less affected by barriers, being better able to occupy suitable habitats compared with sedentary species.

Dispersal might also rescue local populations from extinction (Brown \& Kodric-Brown, 1977) in habitats that are of low quality for orthopterans due to intensive management (Pulliam, 1988). For instance, local disturbance through management strongly affects orthopteran diversity due to the direct mortality of mowing (Humbert et al., 2009), and increased sward height due to fertilisation intensification (Marini et al., 2009a). Thus, highly mobile species should be better able to escape and recolonise the meadows after the disturbance related to management, rendering a generally higher regional occupancy. Loss of sedentary species may not affect $\alpha$-diversity as dramatically as it affects $\beta$-diversity, because $\alpha$-diversity often largely consists of common mobile species, whereas $\beta$-diversity measures diversity responses at larger spatial scales, and is more contingent on sedentary species (Ekroos et al., 2010).

\section{Implications for conservation}

Mobility has been demonstrated to be one of the strongest predictors of widespread decline of orthopteran populations caused by habitat degradation and loss both at the local (Marini et al., 2010) and the biogeographical scale (Reinhardt et al., 2005). Low mobility was associated with higher species turnover across space, particularly at the broader spatial scale. Sedentary species are probably the most threatened species by ongoing land-use changes such as intensification and abandonment. Effective conservation of orthopteran specie richness at the regional scale should therefore consider the mobility-dependent response of species diversity. Previous research has demonstrated that eutrophication (Marini et al., 2009a), disturbance through mowing (Humbert et al., 2009, 2010), and abandonment (Marini et al., 2009b) are major drivers of species richness decline of orthopterans in alpine hay meadows. Conservation measures currently included in most agri-environment schemes have, therefore, focused only on the extensive management of grasslands at the field scale (Knop et al., 2006; Merckx et al., 2009). Our results, however, also indicate that the spatial distribution of these meadows is crucial and that incorporating $\beta$-diversity might provide complementary information to conservation planning to maintain high species diversity at the regional scale. We therefore suggest maintaining extensive meadows scattered throughout the whole region, as the loss of species-rich isolated grassland patches due to abandonment or eutrophication might cause severe reductions of the regional diversity. Increasing connectivity between meadows might be also considered as a complementary measure to improve species occupancy and population persistence, particularly for sedentary species (Ekroos et al., 2010). The inclusion of species mobility in additive partitioning analyses has provided new insights into the processes shaping species diversity, indicating also the relevant scales for optimising future conservation measures.

\section{Acknowledgements}

This work is part of the project 'Management Tools for Biodiversity Conservation in Alpine Agro-ecosystems' fully funded by 'Fondazione Cassa di Risparmio di Trento e Rovereto' (to L.M.). We thank Paolo Fontana (Edmund Mach Foundation) for his help with the identification of orthopterans. We are grateful to L. Rizzi (Cavizzana, TN) for support during the field surveys. We thank Keith S. Summerville and an anonymous reviewer for their insightful comments which considerably improved the quality of the manuscript. R.B. was supported by the EU FP7 project 226852 "SCALES - Securing the Conservation of biodiversity across Administrative Levels and spatial, temporal and Ecological Scales".

\section{References}

Alexander, G. \& Hilliard, J.R. (1969) Altitudinal and seasonal distribution of Orthoptera in the Rocky Mountains of northern Colorado. Ecological Monographs, 39, 385-432.

Bommarco, R., Biesmeijer, J.C., Meyer, B., Potts, S.G., Pöyry, J., Roberts, S.P.M., Steffan-Dewenter, I. \& Öckinger, E. (2010) Dispersal capacity and diet breadth modify the response of wild bees to habitat loss. Proceedings of the Royal Society of Biological Science B, 277, 2075-2082.

Brown, J.H. \& Kodric-Brown, A. (1977) Turnover rates in insular biogeography: effect of immigration on extinction. Ecology, 58, 445-449.

Cowley, M.J.R., Thomas, C.D., Roy, D.B., Wilson, R.J., LeónCortés, J.L., Gutiérrez, D., Bulman, C.R., Quinn, R.M., Moss, D. \& Gaston, K.J. (2001) Density-distribution relationships in 
British butterflies. I. The effect of mobility and spatial scale. Journal of Animal Ecology, 7, 410-425.

Ekroos, J., Heliölä, J. \& Kuussaari, M. (2010) Homogenization of lepidopteran communities in intensively cultivated agricultural landscapes. Journal of Applied Ecology, 47, 459467.

Fontana, P., Buzzetti, F.M., Cogo, A. \& Odé, B. (2002) Guida al riconoscimento e allo studio di cavallette, grilli, mantidi e insetti affini del Veneto (Blattaria, Mantodea, Isoptera, Orthoptera, Phasmatodea, Dermaptera, Embiidina). Museo Naturalistico Archeologico di Vicenza, Vicenza, Italy.

Fontana, P., La Greca, M. \& Kleukers, R. (2005) Ortotteri. Checklist e distribuzione della fauna italiana, Memorie del Museo Civico di Storia Naturale di Verona, Sezione Scienze della Vita 16. (eds by S. Ruffo and F. Stoch), pp. 135-136. Museo Civico di Storia Naturale di Verona, Verona, Italy.

Gabriel, D., Roschewitz, I., Tscharntke, T. \& Thies, C. (2006) Beta diversity at different spatial scales: plant communities in organic and conventional agriculture. Ecological Applications, 16, 2011-2021.

Gardiner, T. \& Hassall, M. (2009) Does microclimate affect grasshopper populations after cutting of hay in improved grassland? Journal of Insect Conservation, 13, 97-102.

Gardiner, T., Hill, J. \& Chesmore, D. (2005) Review of the methods frequently used to estimate the abundance of Orthoptera in grassland ecosystems. Journal of Insect Conservation, 9, 151173.

Gaston, K.J. \& Blackburn, T.M. (2003) Dispersal and the interspecific abundance-occupancy relationship in British birds. Global Ecology and Biogeography, 12, 373-379.

Gering, J.C., Crist, T.O. \& Veech, J.A. (2003) Additive partitioning of species diversity across multiple spatial scales: implications for regional conservation of biodiversity. Conservation Biology, 17, 488-499.

Hanski, I. (1999) Metapopulation Ecology. Oxford University Press, Oxford, UK.

Humbert, J.-Y., Ghazoul, J., Richner, N. \& Walter, T. (2010) Hay harvesting causes high orthopteran mortality. Agriculture, Ecosystems and Environment, 139, 522-527.

Humbert, J.-Y., Ghazoul, J. \& Walter, T. (2009) Meadow harvesting techniques and their impacts on field fauna. Agriculture, Ecosystems and Environment, 130, 1-8.

Ingrisch, S. \& Köhler, G. (1998) Die Heuschrecken Mitteleuropas. Westarp Wissenschaften, Magdeburg, Germany.

Klimek, S., Marini, L., Hofmann, M. \& Isselstein, J. (2008) Additive partitioning of plant diversity with respect to management regime, fertilisation, and abiotic factors. Basic and Applied Ecology, 9, 626-634.

Knop, E., Kleijn, D., Herzog, F. \& Schmid, B. (2006) Effectiveness of the Swiss agri-environment Scheme in promoting biodiversity. Journal of Applied Ecology, 43, 120-127.

Kotiaho, J.S., Kaitala, V., Komonen, A. \& Päivinen, J. (2005) Predicting the risk of extinction from shared ecological characteristics. Proceedings of the National Academy of Sciences, 102, 1963-1967.

Kunin, W.E. \& Gaston, K.J. (1993) The biology of rarity: patterns, causes and consequences. Trends in Ecology and Evolution, 8, 298-301.

Lande, R. (1996) Statistics and partitioning of species diversity, and similarity among multiple communities. Oikos, 76, 5-13.

Littell, R.C., Milliken, G.A., Stroup, W.W. \& Wolfinger, R.D. (1996) SAS System for Mixed Models. SAS Institute Inc., Cary, North Carolina.
Loreau, M. (2000) Are communities saturated? On the relationship between $\alpha, \beta$ and $\gamma$ diversity. Ecology Letters, 3, 73-76.

Marini, L., Bommarco, R., Fontana, P. \& Battisti, A. (2010) Disentangling area and habitat diversity effects on orthopteran species with contrasting mobility. Biological Conservation, 143, 2164-2173

Marini, L., Fontana, P., Battisti, A. \& Gaston, K.J. (2009b) Response of orthopteran diversity to abandonment of semi-natural meadows. Agriculture, Ecosystems and Environment, 132, 232-236.

Marini, L., Fontana, P., Klimek, S., Battisti, A. \& Gaston, K.J. (2009a) Impact of farm size and topography on plant and insect diversity of managed grasslands in the Alps. Biological Conservation, 142, 394-403.

McKnight, M.W., White, P.S., McDonald, R.I., Lamoreux, J.F., Sechrest, W., Ridgely, R.S. \& Stuart, S.N. (2007) Putting betadiversity on the map: broad-scale congruence and coincidence in the extremes. PloS Biology, 5, e272.

Merckx, T., Feber, R.E., Dulieu, R.L., Townsend, M.C., Parsons, M.S., Bourn, N.A.D., Riordan, P. \& Macdonald, D.W. (2009) Effect of field margins on moths depends on species mobility: field-based evidence for landscape-scale conservation. Agriculture, Ecosystems and Environment, 129, 302-309.

Morlon, H., Chuyong, G., Condit, R., Hubbell, S., Kenfack, D., Thomas, D., Valencia, R. \& Green, J.L. (2008) A general framework for the distance-decay of similarity in ecological communities. Ecology Letters, 11, 904-917.

Nekola, J.C. \& White, P.S. (1999) Distance decay of similarity in biogeography and ecology. Journal of Biogeography, 26, 867878.

Nieminen, M., Rita, H. \& Uuvana, P. (1999) Body size and migration rate in moths. Ecography, 22, 697-707.

Novotny, V. (2009) Beta diversity of plant-insect food webs in tropical forests: a conceptual framework. Insect Conservation and Diversity, 2, 5-9.

Öckinger, E., Franzén, M., Rundlöf, M. \& Smith, H.G. (2009) Mobility-dependent effects on species richness in fragmented landscapes. Basic and Applied Ecology, 10, 573-578.

Öckinger, E., Schweiger, O., Crist, T.O., Debinski, D.M., Krauss, J., Kuussaari, M., Petersen, J.D., Pöyry, J., Settele, J., Summerville, K.S. \& Bommarco, R. (2010) Life-history traits predict species responses to habitat area and isolation - A cross-continental synthesis. Ecology Letters, 13, 969-979.

Olsen, S., Cole, C., Watanabe, F. \& Dean, L. (1954) Estimation of Available Phosphorus in Soils by Extraction with Sodium Bicarbonate. USDA Circular 939, US Gov. Print. Office, Washington, District of Columbia.

Poniatowski, D. \& Fartmann, T. (2008) Experimental evidence for density-determined wing dimorphism in two bush-crickets (Ensifera: Tettigoniidae). European Journal of Entomology, 106, 599-605.

Pulliam, H.R. (1988) Sources, sinks, and population regulation. American Naturalist, 132, 652-661.

Reinhardt, K., Köhler, G., Maas, S. \& Detzel, P. (2005) Low dispersal ability and habitat specificity promote extinctions in rare but not in widespread species: the Orthoptera of Germany. Ecography, 28, 593-602.

Schirmel, J., Blindow, I. \& Fartmann, T. (2010) The necessity of habitat mosaics for Orthoptera (Caelifera, Ensifera) in dry heathlands. European Journal of Entomology, 107, 129-132.

Schouten, M.A., Verweij, P.A., Barendregt, A., Kleukers, R.M.J.C. \& de Ruiter, P.C. (2007) Nested assemblages of Orthoptera species in the Netherlands: the importance of habi- 
tat features and life-history traits. Journal of Biogeography, 34, 1938-1946.

Stewart, K.E.J., Bourn, N.A.D. \& Thomas, J.A. (2001) An evaluation of three quick methods commonly used to assess sward height in ecology. Journal of Applied Ecology, 38, 1148-1154.

Summerville, K.S., Boulware, M., Veech, J.A. \& Crist, T.O. (2003) Spatial variation in species diversity and composition of forest Lepidoptera: patterns and implications for conservation. Conservation Biology, 17, 1045-1057.

Summerville, K.S., Wilson, T.D., Veech, J.A. \& Crist, T.O. (2006) Do body size and diet breadth affect partitioning of species diversity? A test with forest Lepidoptera Diversity and Distributions, 12, 91-99.
Thomas, C.D. (2000) Dispersal and extinction in fragmented landscapes. Proceedings of the Royal Society of Biological Science $B, \mathbf{2 6 7}, 139-145$.

Tscharntke, T., Klein, A.M., Kruess, A., Steffan-Dewenter, I. \& Thies, C. (2005) Landscape perspectives on agricultural intensification and biodiversity - ecosystem service management. Ecology Letters, 8, 857-874.

Accepted 7 December 2010

First published online 11 October 2011

Editor: Simon R. Leather

Associate editor: Alan Stewart 